\title{
African Adolescent Males and Rape in the Eastern Cape, South Africa: A Need for Sexuality Education
}

\begin{abstract}
J.G. Kheswa
X. Dayi

P. Gqumani

Department of Psychology, University of Fort Hare, Private Bag X 1314, Alice, 5700

Email: jkheswa@ufh.ac.za

Doi:10.5901/mjss.2014.v5n10p541

Abstract

Adolescent males are most likely to rape when raised in communities characterized by low levels of morality; where adults perpetrate violence against women, schools are disorganized, parents are dysfunctional and culture oppresses the rights of women. Such youth tend to sexually assault others, lack empathy, are aggressive, manipulative and engage in risk-taking behaviours (multiple- sexual partners, unsafe sex, and substance abuse). The researchers intended to investigate the impact of culture on rape by adolescent males. The participants of the study comprised 18 male adolescents which have been selected purposively in Ntselamanzi village, Eastern Cape, using an explorative, descriptive qualitative research design. The findings of this study show that there is an urgent need for sexuality education for South African youth, since the participants revealed that their sexual prowess is influenced by hegemonic masculinity, substance abuse and mass-media.
\end{abstract}

Keywords: adolescent males, rape, cultural norms, imprisonment, sexuality education.

\section{Introduction}

South Africa has got a high rate of sexual offences among adolescent males in the world (Mawson \& Basson, 2011; Petersen, Bhana \& McKay, 2005). Adolescent males are most likely to rape when raised in communities characterized by low levels of morality; where adults perpetrate violence against women, schools are disorganized, parents are dysfunctional and culture oppresses the rights of women (Holborn \& Eddy, 2011; Kann, 2008; Morkel, Wibbelsman, \& Seigal, 2011). According to Jewkes, Skweyiya, Morrell and Dunkle (2006), rape refers to any sexual act, attempt to obtain a sexual act, unwanted sexual comments or advances, or acts to traffic, or otherwise directed against woman's sexuality, using coercion (i.e., psychological intimidation, physical force, or threats of harm), by any person regardless of relationship to the victim, in any setting, including home, school and work. In many African cultures, Jeriphanos, Kudakwashe and Phinias (2004), found that if a woman or a girl says "no" to sex, it means the opposite hence the result would be acquaintance rape. Furthermore, Petersen et al., (2005), found that, in relation to cultural/environmental influences, boys were reportedly socialized from an early age into traditional patriarchal notions of masculinity, which promote and legitimize unequal gendered power relations. Malan (2013) asserts that gender hierarchy and males' perception of what it means to be a man, contribute to sexual aggression of adolescent males to devalue the worth of females by being violent and less agreeable to negotiating safe sex with their partners- the stereotype that is in contrast with what feminist theory advocates.

\section{Personality Traits of Adolescent Males Who Rape}

According to Netland (2010), adolescent males with the tendency to sexually assault others, lack empathy, are aggressive, manipulative and engage in risk-taking behaviours (multiple- sexual partners, unsafe sex, substance abuse). They prefer forming friendship with individuals older than them, not attending school, and who are into substance abuse (e.g.marijuana and alcohol) (Louw \& Louw, 2007). Given that they must conform to their peers, they become exposed to incorrect information about healthy sexual behaviour and end up raping girls against the will especially when under the influence of alcohol and drugs, and that is statutory rape (Larsen, 2008; Wilson, Fitzharris \& Morrissey, 2004). For instance in a study of just over 1500 Grade 8-10 pupils in Cape Town, South Africa, Holborn and Eddy (2011) found that those who reported using drugs had higher rates of aggression, depression and generic mental problems which in return makes them to unconsciously become rapists. 
According to Flores (2005) statutory rape is a general term to describe an offense that takes place when an individual regardless of age has consensual sexual relations with an individual not old enough to legally consent to the behaviour. Jewkes, Sikweyiya, Morrell and Dunkle (2006) in the study conducted in Eastern Cape and KwaZulu Natal in order to understand rape perpetration, established that $27 \%$ of adolescent males agreed that they had forced minors to have sex with them against their will. In Soweto, Gauteng Province 5\% of females got raped before the age of 15 years, $12,4 \%$ raped the first time they ever had sex and $20,1 \%$ had been forced or threatened into sex by their boyfriends. From these alarming figures adolescent males could be hypothesized as being at risk of being imprisoned and contracting sexually transmitted infections.

\section{Differential Theories Explaining Rape by Adolescent Males}

In this study, social learning theory, gender-strain theory, and ecological theory will provide the underlying reasons why adolescent males rape. According to Corey (2009), social learning theory by Bandura, stresses that an individual conforms to environmental influences. Social learning is all about modelling, observation and imitation of a certain behaviour (Cherry, 2013; Hill, Song, \& West, 2009; Henning, 2004, Weiten, 2011). According to Underwood, Robinson, Mosholder and Warren (2008), witnessing domestic violence at an early age by adolescent males is inextricably linked to sexual behaviour. For example, Asaph, Karen and Mike (2004) contend that adolescents who are products of domestic violence, from younger age are more likely to sexually coerce females as young as age 14. Underwood et al., (2008), state that adolescent male sex offenders are associated with poor parental support and antisocial male-modelled behaviour, According to the gender strain theory pioneered by Robert Agnew in 1992, Agnew (2006) contends that there are three key dimensions to gender strain theory, strain, negative emotionality and coping resources. Strain occurs from failed personal goals and removal of positive stimuli. Strain as a result can be a contributory factor to sexual offending. Jang (2007), posits that such youth turn to deviance coping strategies when experiencing strain partly because their strains are more likely to generate self-directed emotions. Males are more likely to be arrested for serious property offences, drugs, and violent offenses and this illustrate that males are more likely to respond to a given level of strain/ emotional distress with crime. According to Bronfenbrenner's $(1979 ; 1986)$ ecological model, adolescents are influenced by their immediate context such as the family, peer group, classroom, community and neighbourhood, as well as broader systems such as cultural values and social conditions.

\subsection{Family setting}

Manlove, Logan, Moore and Ikramullah (2010) documented that families with higher levels of religiosity are likely to have obedient children than other teenagers from different families to avoid early sexual behaviour and the associated risks of STIs. However, Bezuidenhout and Joubert (2008), point out that the poorer the adolescents' interactions with their family members, the higher the possibilities that such youth may engage in risk- taking behaviour. Kopko (2007) highlighted that uninvolved parents lack secure attachment and affection towards their children as compared to authoritative parents. They are unaware of the adolescent's needs and become uninvolved to the point of being neglectful (Louw \& Louw, 2007; Pastorino \& Doyle- Portillo, 2011) which, in turn, adversely affecting self- regulation and self-esteem of the adolescents (Weiten, 2011). Drawing from the family systems theory, when the family is disengaged and pays no attention to the psychological wellbeing of adolescents nor imparts sexuality education, negative expectations are that adolescent males will have a negative evaluation of the self and experience difficulty in establishing emotional connectedness with their sexual partners (Abesha, 2012; Anyawu, 2011). The danger is that the neglect may resurface in the form of aggressive behaviour and contributes towards deindividuation of the adolescent male (Kassin, Fein \& Markus, 2011). According to Holborn and Eddy (2011), adolescent sexual offenders are the outcomes of dysfunctional families as the absence of a parent in the development of the child has a great impact on the adolescent's sex attitude and relationships. Jewkes (2012) found that child abuse was five times more common among adolescent sexual offenders than among adolescent non- offenders. Sexual offenders against children were much more likely to have histories of sexual abuse than non -sexual offenders.

\subsection{Cultural norms}

In a South African research conducted by Peacock, Redpath, Weston, Evans, Daub and Greig (2008), social construction of manhood has strong effects on men's health. It affects women directly, for example via male violence against them causes physical and psychological harm, and indirectly through men's risky behaviour increases their female partner's 
vulnerability to sexual transmitted diseases. In most cases this is perpetrated in societies which are cultural and perceiving females as sex-objects. For example, Gwata (2009) found that majority of adolescent males who underwent traditional male circumcision appear to drink alcohol and sexually coerce females as one form of expressing their masculinity because they have obtained social status of being a man "indoda". According to Gaya (2010) in the community, when call by the young, they are being addressed as "bhuti" as a sign of respect to those who are already men, as compared to uncircumcised men of their age. Coupled with peer pressure, those with weak locus of control, according to Breet, Myburgh and Poggenpoel (2010) they would disrespect parents, bully others at school and have multiple sexual partners.

\subsection{Environment}

Growing up in a fractured environment which is characterized by poverty, crime and violence, may drive adolescent males to abuse drugs and eventually gang- rape ( Holborn \& Eddy, 2011; Kalichman, Simbayi, Kagee, Toefy, Jooste, Cain \& Cherry, 2006). These behaviours emanate from a lack of appropriate law enforcement which has been found to contribute to the prevalence of teenage - drinking and women abuse. Such youth may lack self-actualization, self-control, cognitive stimulation and intrinsic motivation. Unlike non-sexual offenders, who become resilient in the face of adversity (e.g. divorce of parents, unemployment of parents, academic failures), these adolescents become neurotic, introverted and socially withdrawn (Costa, 2008; Ryckman, 2008). At school, their attendance is poor, likely to repeat grades and bully others, and act impulsively (Louw \& Louw, 2007).

\section{Effects of Rape}

According to Jemmott, Heeren, Ngwane, Hewitt, Shell, and O'Leary (2007), rape may lead to dropping out at school prematurely, unplanned fatherhood, imprisonment and contracting of sexually transmitted infections (STIS) including HIVIAIDS. Freeman and Temple (2010) in their study found that sexual assault victimization by adolescent males is associated with their negative outcomes including poor academic, involvement in sexual risk taking behaviours, and interpersonal problems. Weisz and Black (2009), documented adolescent males who rape experience unplanned fatherhood due to the sexual behaviours during the puberty stage and this is a consequence because they are not financially, emotionally and psychologically ready to become fathers yet. Furthermore, Bachrach and Sonestein (2002), stress that adolescent males who are fathers as a result of rape do not comply with the traditional notion of what it means to be a father, because of their age and lack of resources to provide for their families. Consequently, they are likely to languish (i.e. struggle and have negative self- esteem, experience depression and have suicidal ideation (Comer, 2009; Deci \& Ryan, 2006). And finally when teenage parents cohabit, problems become more frequent and physical abuse is most likely (Holborn \& Eddy, 2011; Zastrow \& Kirst-Ashman 2007). Though while in prison sexual offenders are entitled to enrol to further their studies according to the Bill of Rights, section 29 which stipulates that every South African has the right to equality and education (Constitution of the Republic of South Africa, 1996), Torerai (2013) found that that exoffenders in Klerksdorp, Free-State Province, South Africa were struggling to find employment after they had served their term in prison. Another challenge is that they are stigmatized and reintegrate to the society. Against this background, the researchers intended to investigate the following research questions;

- How does culture impact on rape by adolescent males?

- How does peer influence contribute towards rape among adolescent males?

- What are the consequences of rape among adolescent males?

\section{Research Method}

The researchers used an explorative, descriptive qualitative research design in their study. Qualitative research is a type of research designed to explore and get an understanding of the meaning participants give as individuals or groups about a human or social phenomenon. Qualitative research is known to use methods such as ethnography, phenomenological research, case studies and narrative method (Creswell, 2008).

\section{Research Population and Sample}

The target population of the study was in Ntselamanzi village from one secondary school, Nkonkobe District, Eastern Cape of South Africa. The participants of the study comprised 18 male adolescents which have been selected 
purposively. The data collection process took place at the school where the participated learners were attending. According to Golafshani (2008) a sample is a selected part of the larger population. Purposive sampling was used since the researchers were deliberated to study only adolescent males who rape. The participants of the research study were informed about the objectives and the significance and gave informed consent to participate voluntarily in the study.

\section{Instruments}

The researchers used an in-depth interview as an instrument to collect data in the study. According to Guion, Diel and McDonald (2011) in-depth interviews are the useful qualitative data collection methods that can be used for a variety of purposes including needs assessment, program refinement, issue identification and strategic planning.

In-depth interviews were chosen because of the following advantages:

- it assists in complex issues to be probed.

- answers can be clarified.

- sensitive information can be obtained.

- provides much more detailed information than what is available through other data collection methods such as survey.

- provides more relaxed atmosphere to collect data information, people or participants may feel more comfortable having a conversation with researchers about the program or project as opposed filling out a survey ( Leedy \& Ormrod, 2005).

\section{Trustworthiness}

The researchers used credibility, conformability, transferability and dependability in their study to ensure reliability/ trustworthiness in their study (Shenton, 2004).

\subsection{Credibility}

According to Sinkovics, Penz and Ghauri (2008), credibility is defined by Guba and Lincoln (2005) as being parallel to internal validity. It focuses on establishing a match between the constructed realities of respondents and those realities represented by the researcher(s). Furthermore, Wahyuni (2012) states that credibility deals with the accuracy of data to reflect the observed social phenomena.

In simple terms, credibility is concerned with whether the study actually measures or tests what is intended.

\subsection{Transferability / Generalisability}

Carcary (2009) define generalizability as concerned with how applicable theories, which are generated in one setting are to other settings. Therefore, the researchers used 18 participants and have a view that the data collected can be generalized to the entire population.

\subsection{Dependability}

According to Graneheim and Lundman (2004) dependability refers to the stability of a research inquiry. This process involves consistent data collection, clear presentation of findings and evaluation of the process by the researchers. Shenton (2004) constitutes that dependability can be determined if the research design is used as a prototype model and all data is reported in detail.

\subsection{Conformability}

Conformability refers to the extent to which others can confirm the findings in order to ensure that the results reflect the understandings and experiences from observed participants, rather than the researcher's own preferences (Wahyuni, 2012), Researchers had used the audit trial to ensure that they have confirmation of their study, Cacrary (2009) states that an audit trial is a transparent description of the research steps taken from the start of a research projects to the development and reporting of findings. 


\section{Ethical Consideration}

In this study the researchers have ensured the informed consent, confidentiality and anonymity of the participants, are adhered to. The school principal was informed and asked for permission (in the form of an official letter from the Faculty of Social Science and Humanities, University of Fort Hare) to conduct the study among adolescent males that perpetrate sexual offences. The school principal gave consent and the qualified Life Orientation teacher was asked to identify those adolescent males. The adolescent males were informed about the aim of the study and also gave consent through signing a consent form. The adolescent males were given an opportunity to withdraw anytime they feel like or feel uncomfortable to continue with the research, as suggested by de Vos et al., (2012). Confidentiality, privacy and anonymity were guaranteed to the participants prior the research. The process of data collection took place in the month of October 2013 and it was the time when there were few extraneous activities at school. We were allocated one of the classrooms and since there was electric plug to switch on the recording device, that contributed to the efficiency of the research. Participants were also assured that once coding has taken place, the chief- researcher will destroy the information.

\section{Analysis and Discussion of Research results}

The researchers used coding to analyze the data. According to Creswell (2007), coding is defined as marking the segment of data with symbols, descriptive, words or category names. Furthermore, de Vos et al., (2012) define coding as a simultaneous activity of data reduction used to categorize or organize data into manageable work. According to Graham (2007) coding gives opportunity for the researchers to summarize their data. After re-reading the transcripts for several days, the researchers invented some themes that have been perceived to be playing a significant role in leading adolescent males to sexually offend girls.

Some of these themes that have been identified and invented by the researchers are discussed as follows:

\subsection{Gender inequality}

Entitlement to male dominance and power resulted in adolescent males claiming no respect for females because when they were interviewed it was found that they do not rape the girls because they want to, but they feel that girls need to be taught respect. They cited the following responses:

"My friends and I don't respect girls because others are undermining us, thus we end up raping them in order to discipline those undermining us."

"We assume girls are weak and have the advantage to sleep with them to be satisfied."

"In our culture men are superior to women."

The research findings are in congruent with the study by Kaufman, Kaufman, Dringus, Weiss, Delany-Moretlwe and Ross (2013), conducted among Xhosa-speaking adolescent males in Cape- Town and Port-Elizabeth townships in Eastern Cape. In a quantitative study, Kaufman and his colleagues found that of 1991 Grade 9 learners with the mean age of 16 years, $17.2 \%(\mathrm{~N}=342)$ reported having perpetrated rape. The adolescent males cited the following reasons as the factors which caused them to rape girls; having been traditionally circumcised, growing up in a male-dominated society, and having fathers with no secondary education. The notion is that for as long adolescent males are not being equipped with moral education, cognitive- behavioural skills and interpersonal conflict management, African cultures will be devalued as compared to Western cultures which inculcates discipline, self- respect and prosocial behaviour.

\subsection{Sexually Risk-behaviours}

The participants reported that they actually do not take into consideration things such as STIs when they engage themselves in the raping process. This is figured out when they responded to the question "Have you considered the dangers or medical risky of sexual offence or rape (e.g. non condom use, STIs)"?

Participants appeared saying that:

"Yes I am aware, but during that time when you rape a girl especially the one you want the most things like statutory rape and STIs do not come to my mind".

"No I never thought about any danger because when you have used drugs, you just do it without carrying condoms and you want an immediate gratification, yes I thought about such things like getting STIs because I do not know about her status it does not stops me"

These responses prove the fact that adolescent males who rape are sexually risk takers. According to Moodley, 
Matjila and Moosa (2010) it is evident that excessive alcohol use and illicit substance use impair reasoning ability, contribute towards criminal behaviour. According to Jemmott et al., (2007), in societies which are drug-friendly, rape will escalate and the government will have to spend much of the taxpayers' money because majority of youth will end be imprisoned and HIV- positive, as a result of sexually risk behaviour.

\subsection{Lack of communication and trust amongst the family}

Adolescent males who indulge themselves in rape tend not to have good and open communication with their family members whereas family is the first agency of socialization. A psychoanalytic explanation for lack of communication and trust at family level could be that the perceived neglect experienced during childhood may have contributed in adolescent males not to form attachment with parents (De Vore \& Ginsburg, 2005; Kjellgren, Priebe, Svedin \& Langstrom, 2010). This theme emerged as a result of the question that says "Describe your relationship with your family members with respect to valuing sexual relationships (e.g. trust, love detachment)"

Participants replied as follows:

"The relationship with family is not good, I stay with my mother and sibling, so she does not have time for me so that is why I behave the way if do and also at home they do not trust me they think that I might rape my siblings"

"I live with my grandparents, my father and cousins and I am not close with my family members and we do not communicate about sexual related issues"

"No I do not communicate with my family about sex issues or sexual relationship issues

"I do not communicate with my family about sex relationship, I feel ashamed and tense".

From the responses of the participants it is clear that adolescent males who sexually offend girls come from uninvolved parents. This logic is supported by empirical studies about parental involvement in their sexual behaviour of their sons. Holborn and Eddy (2011), agree that when discussions of sexuality is difficult for parents, young people become influenced by peers and get incorrect information about sexuality. Furthermore, when parents do not instil morals by being principled themselves, Barni, Ranieri, Scabini and Rosnati (2011), emphasize that such youth might attempt to practice incest.

\subsection{Substance abuse}

From the data that has been collected, the adolescent males who reported to be sexually offending girls, were driven by substance abuse. They become brave and confident when they are under the influence of substance abuse. For instance, in the question, "Explain what drives you to engage in risky sexual behaviour"? The responses were as follows.

"What drives me to engage in risky sexual behaviour most of the time is alcohol because it makes me not to think straight."

"Drugs drive me to engage in risky sexual behaviour because they make me brave and to gain confidence in what I do." "Smoking harmful substances, use of drugs like pills lead me to rape."

These findings are congruent with the several studies that have reported a direct link between males' alcohol and other drugs and perpetration of rape (Brook, Morojele \& Brook , 2006; Jewkes, 2012). For instance, in a study conducted in two large Cape- Town's townships, Khayelitsha (which is predominately black Xhosa-speaking), and Mitchell's Plein (which is predominately Coloured community) by Wechsberg, Myers, Reed, Carney, Emanuel and Browne (2013), women between age 18-45 years old, confirmed that drugs such as 'tik' steer the males' behaviour and make them to sexually aggressive. Drawing from alcohol myopic theory, it means that since their consciousness is impaired, it is clear that they could contract HIVIAIDS owing to non-condom use.

\subsection{Sexually seductive behaviour of females}

Most of the adolescent males that were interviewed expressed that females also play a role in them being raped because they seduce them especially when they are at the taverns during weekends. Such girls wear miniskirts or sit on the males' laps so that the males can buy them drinks. The statement above is supported by some of the responses such as these:

"Girls who wear short skirts tempt me that I can't control myself but to engage in sexual behaviour."

"Males assume that the girls are interested in them because they sit on their lap and wanting drinks, so males assume they will leave with them and have sex."

"I engage in sexual behaviour because girls are beautiful and wear short skirts."

In an article by Gagnon (2006), seduction has become a regularly a power trip, and quickly leads to explicit sexual 
behaviour. For example, females wear tempting clothes, dance seductively when under the influence of alcohol, make direct offers, and assume stimulating poses. This is clear that some adolescent males are easily seduced by the manner at which girls wear their clothes which eventually lead them to indulge themselves in raping activities. According to Testa, Hoffman, Livingston and Turrisi (2010), adolescent males take an advantage of what is called incapacitated rape- which refers to a non-consensual sex that occurs as a result of the females' sexually provocative actions, their drinking to a point of unconsciousness or incapacitation, and being unable to resist sexual advances.

\subsection{Conformity}

Conformity seemed to be most common among the adolescents that were interviewed in a sense that most of them cited that they rape because they want to fit in, to gain trust or to be regarded as masculine by peers. For example, in a question "How have your peers contributed to behaviour in sexually offending girls"? The responses were:

"My friends have a view that I do not trust myself and end up not trusting me so I end up doing what they say so that they can trust me."

"Friends contribute the most in influencing in me because if you do not do what they are doing or want they say you are weak."

"Peer pressure drives me to rape like listening to friends, and doing it in order to fit in the group."

Wechsberg et al., (2013), have documented that most adolescent males who rape, are crowd-pleasers and disregard the legal consequences. To confirm this, Langa (2012), in the research study conducted in Alexandra Township in Gauteng Province, South Africa, to assess the reasons for conformity among adolescent males, the responses were:

- In achieving the status of s'khokho (township slang for hero), one must carry a weapon (e.g. a knife) to school in order to gain respect among peers.

- When one is rebellious against educators, it is easy to have romantic relationships with girls of your choice without having competitors.

\subsection{Guilty consciousness}

Some respondents reported to feel guilty after sexually offending girl. When the questions asked from them which says "Describe your emotional experience while or after sexually offending girls (e.g. self esteem, empathy")?

"After I have done it, I feel very guilty because she did not give me permission to do it"

"I feel happy after rape because you got what you wanted but as time goes you start to feel bad".

"I feel guilty, be shocked to develop fear and sorrow"

This shows that some other adolescents males who sexually offend girls also consider the value of females but because of certain aspects such as peer influence, substance abuse and externalized locus of control they end up engage themselves on this phenomenon of rape. According to Cullen (2011) sexually offending adolescent males are characterized by the lack of predisposing personality factors which include mainly to the social skill, self- control, self esteem and empathy.

\subsection{Lack of empathy (during sex)}

Non empathetic attitude during sex has been identified from the adolescent males who sexually offend girl. Some of them reported to the question "Describe your emotional experience while or after sexually offending girls (e. g self esteem, empathy"? as follows:

"After offending sexually offending a girl I do not feel anything like being sympathetic but I have feeling of being a man" and also respondent reported that

"I feel very good after raped her and I had no regrets for that".

"I became very happy after offending her because I felt satisfied and got what I wanted from her".

"you feel good after sexually offending, secure and happy especially when you are not drunk because you got what you intended to get".

This means that some adolescent males are sexually offending girls deliberately for the fact that they do not feel any empathy

\subsection{Non cyber bullying}

The participants stated that they have never threatened girls through social networks such as facebook, mxit, watsapp, 2go, badoo, twitter, blue world, pep text, etc. This emerged from the question that said "Have you ever threatened girls by 
using cellphones (e.g. face book, whatsapp, mxit) demanding sex"?

And the responses were as follows:

"No I never threatened any girls using social networks because I am afraid that she might save messages and show the police to get me arrested"

"No I never I hate that very much because I do not get good satisfaction as much as I want from that I wanted the real deal"

"I do not threaten a girl via social network because she will know that I am intending to rape her I just attack her when we meet"

"I never threatened a girl via social networks"

This clearly shows that adolescent males who sexually coerce females are typically psychopaths. They know that the use of cellphones or advanced technology to bully or threaten their victims could lead them to imprisonment. Their responses fit the description of psychopaths are, according to Robert Hare (Hare, 2003). He identified the personality traits of a psychopath as being confident, emotionally shallow, impulsive, manipulative, irresponsible, and lacking feelings of remorse. Furthermore, when asked if they are aware of the criminal /legal implications of raping girls under the age of 18 (e.g. statutory rape and date rape), they responded as follows:

"Yes, I am aware, but it is nothing serious to me because the Criminal Justice of this country is so weak, it is something not major to me".

"I do not know what statutory rape is and what date rape is, but I know that rapists end up in prison"

\subsection{Television as the most contributory factor}

Most participants reported that mass media plays a major role in making them end up offending girls, but specifically television because that is where they watch movies (romantic movies), Dramas like yizo-yizo that portray love, rape and violence. With regards to the question"How has mass media contributed to your behaviour in sexually offending young girls"?

The participants responded as follows as follows:

Mass - media has an impact on my sexual offending because for instance after watching yizo-yizo, smoking or drinking, I develop some sexual feelings [ukubatywa] where I might end up raping even your sister"

"Mass media has an impact because they see people kissing in Generations, watch pornography and tend to imitate that to test and prove themselves as men"

"we as males are copying on what we see in movies and music videos then assume that girls are supposed to be like those we see on television and acting like them also like in pornography, hence we force sex upon them"

This is actually in line with the fact that television as the type of mass media plays a major role to the sexually offence of girls. In a study by Bahr, Hoffmann and Yang (2005) it was established that learning takes place during interaction with friends as well as through mass media. Similarly, according to the research findings by Clive (2004) based on Yizo-Yizo, a popular drama screened on SABC 1 in South Africa, (which portrays violence, sexual harassment and drug abuse), adolescent males admitted that they sexually offend girls. They drew antisocial skills from viewing male characters when engaged in criminal activities.

\section{Possible Limitations}

Race was one of the limitations in the research study since it constituted participants, (aged 16-19 years) of the same culture (Xhosa-speaking in one village) from the Eastern Cape. Participants also gave information more on the impact of their culture in sexual offending girls. However, the findings can be generalized to a large population based on the literature supporting our empirical research.

\section{Way Forward}

The researchers recommended family, and the community to take part in preventing rape. Rape can be prevented if the family and the community can make sure that sexual offences that take place in those settings are reported to the police so that perpetrators can be arrested.

At family level, a warm and secure environment which inculcates values and morals to adolescence may encourage males to devote much time to their studies and sports as opposed to a hostile environment where they witness violence, thereby developing antisocial behaviour. According to Taylor (2013), when parents function as primary prevention force in their children's psychosocial well-being, countering the rape myths and rape-accepting attitudes, through connecting emotionally with their children, young people may acquire values and grow knowing that women have 
their indelible right to dignity. Since sexuality education is integrated in the curriculum, it is imperative that children may be taught the dangers of rape (e.g. STI's, imprisonment and unplanned fatherhood) so that the stereotypes about demeaning females maybe corrected.

The researchers recommend social workers to play a role in preventing male adolescents' rape in these following ways:

Rape can be prevented through educating people about rape in the form of awareness campaigns. Social workers also can prevent rape through doing proper assessment and try to figure out about the contributory factors to male adolescents' rape. After assessment if the social workers have found that the male adolescents resort to rape because they are in need of care, for instance in the case of orphans and child headed households, the researchers recommend social workers to place the male adolescents in foster care or to take them to the children's homes.

The social workers can also play a role in rape prevention through referring male adolescents to psychologists if found committing sexual offences due to psychological problems, and give counselling to male adolescents who rape owing to substance abuse and family matters or to refer him to the drug and alcohol programs.

The researchers suggest a way forward that, the research study of the adolescent males rape should be further researched in order to come up with other factors that might be leading adolescent to indulge themselves in rape activities and impose more recommendations based on this issue of adolescents male rape.

\section{Acknowledgement}

This research study was financially supported by Govan Mbeki Research Development Centre, University of Fort Hare.

\section{References}

Abesha, A.G. (2012). Effects of Parenting Styles, Academic self efficacy, and Achievement motivation on the academic achievement of University Students. Edith Cowan University: Ethiopia.

Agnew, R. (2006). Pressured into crime: an overview of general strain theory. Roxbury: Los Angeles

Anyanwu, J.I. (2011). Parental Relationships as a Correlation of Psychological wellbeing of South Eastern Adolescents. Department of Educational Foundations.University of Nigeria:Nsukka.

Asaph, G., Karen,G. \& Mike F. (2004). Statutory Rape: A guide to State laws and Reporting Requirements. Department of Health and Human Sciences.

Bachrach, C., \& Sonenstein, F. (2002).Report of the working group on male fertility and formation.

Bahr, J.S, Hoffmann J.P \& Yang, X. (2005). Parental and peer influences on the risk of adolescent drug use. Journal of Primary Prevention. Volume 26, no.6: Springer Science and Business Media Incorporated.

Barni, D., Ranieri, S., Scabin, E., \& Rosnati, R. (2011). Value transmission in the family: do adolescents accept the values their parents want to transmit? Journal of Moral Education, Vol 40 (1), 105-121. Doi.10.1080/03057240.2011553797.

Barry, T.D. \& Lochman J.E. (2008) Aggression in adolescents: Strategies for Parents and Educators.

Bezuidenhout, C., \& Joubert, S. (2008). Child and youth misbehaviour in South Africa. Pretoria: Van Schaik publishers.

Boyce, C., Neal, P. (2006). Conducting in-depth interviews: a guide to for delinquency and conducting in-depth interviews for evaluation input. Pathfinder International.

Breet, L., Myburgh, C. \& Poggenpoel, M. (2010). The relationship between the perception of own locus of control and aggression of adolescent boys. South African journal of education: 30,511-526.

Brook, J.S, Morojele, N.K., Brook. D. (2006). Predictors of Drug Use among South African adolescents. Journal of adolescent health. 38(1): 26-34

Cherry, K. (2013). An Overview of Bandura's Social Learning Theory. Jack Meams Publication.

Clive, B. (2004). Yizo-Yizo: Citizenship, Commodification and Popular Culture in South Africa. University of Bistol

Comer, R.J. (2009).Abnormal Pyscology.(8 ${ }^{\text {th }}$ Edition). Worth Publishers: New York.

Corey, G. (2009). Theory and Practice of Counseling and Psychotherapy. Belmont.

Costa, F. (2008). Problem Behavior theory: a brief overview. University of Colorado.

Creswell, J. W. (2007). Qualitative Inquiry and Research Design: Choosing Among Five Approaches. (2 ${ }^{\text {nd }} \mathrm{Ed}$.). Sage Publications: Thousand Oaks

Carcary, M. (2009).The Research Audit Trial- Enhancing Trustworthiness in Qualitative Inquiry: The Electronic Journal of Business Research Methods. Volume 7 (1), 11-24

Cullen, P. (2011). An investigation into personality typologies of adolescent sexual offenders. University of Birmingham: United Kingdom.

Deci , E.L. \& Ryan, R.M. (2006). Hedonia, Eudaimonia, and Well-Being: An

Introduction. Journal of Happiness Studies, (9), 1-11.

De Vore, E.R., \& Ginsburg, K.E. (2005). The protective effects of good parenting on adolescent. Current opinion in Pediatrics, Vol 17, 460-465.

de Vos, A.S., Fouche, C.B., Strydom, H. \& Delport, C.S.L. (2011). Research at grass roots. Van Schaik: Pretoria.

Flores, J.K. (2005). Statutory rape known to law enforcement. US Department of Justice

Freeman, D.H. Jr., \& Temple, J.R. (2010).Social Factors Associated with History of Sexually Assault Among Ethically diverse Adolescents. Medical Branch, Family Violence.University of Texas: Texas

Gagnon, G. (2006) The sex educator magazine. Issue 5

Graham,G.( 2007). Analyzing Qualitative Data. Centre for Evaluation \& Research, Trinidad: Tobacco

Graneheim, U.H., \& Lundman, B. (2004). Qualitative content analysis in nursing research: concepts, procedures and measures to achieve trustworthiness. Department of Nursing, Umea University: Sweden

Guion, L.A., Deihl, D.C.,\&Mcdonald, D.C. (2011).Conducting an in-depth interview.IFAS Extention,University of Florida: Florida

Golafshani,N. (2003).Understanding reliability and validity in qualitative research. The Qualitative Report, 8(4):597-606. University of Toronto: Canada 
Guba, E.G., \& Lincoln, Y.S. (2005). Paradigmatic controversies, contradictions, and emerging confluences. In Denzin N.K. \& Lincoln Y.S. The Sage handbook of qualitative research. (3rd Edition), pp 191-215. Thousand Oaks: California

Gwata, F. (2009).Traditional male circumcision: what is its socio-cultural significance among young Xhosa men? Aids and Society Research Unit.

Henning, W. (2004). Everyday cognition and situated learning. Handbook of Research on Educational communications and Technology, (2nd Ed).

Hill, J. R., Song, L., \& West, E. R. (2009). Social Learning Theory and Web-Based Learning Environments: A Review of Research and Discussion of Implications. American Journal of Distance Education, 23:2, 88-103

Holborn, L. \& Eddy, G. (2011). First Steps to healing the South African Family. A research paper by the South African Institute of Race Relations, Johannesburg. South Africa.

Jang, S.J. (2007). Gender differences in strain, negative emotions and coping behaviors: A general strain theory approach. Journal of Criminal Justice, 24, $523-553$

Jeriphans, M., Kudakwashe, M., Phinias, T. (2004). Influences of culture on acquaintance rape among college students. Thesis, Zimbabwe University: Harare

Jemmott, J.B., Ngwane, Z., Hewitt, G. A., Jemmott, L.S., Shell, R., \& O'Leary, A. (2007). Theory of planned behavioral prediction of intention to use Condoms among xhosa adolescents in South Africa. Mdantsane: East London

Jewkes, R. (2012). Rape perpetration: a review in Pretoria, Sexual Violence Research Initiative. Pretoria: South Africa.

Jewkes, R., Nduna, M., Shai, N. J., \& Dunkle, K. (2012). Prospective study of rape perpetration by young South African men: incidence \& risk factors. PloS one, 7(5), e38210.

Kalichman, S.C., Simbayi, L., Kagee, A., Teofy, Y., Jooste, S., Cain, D., \& Cherry, C. (2006). Assosciations of poverty, substance use and HIV transmission: risk behaviours in three South African communities. Journal of Social Science and Medicine, 62: 1641-1649

Kann, L. (2008). A dangerous game male adolescent's perceptions and attitudes towards sexual consent. University of Witwatersrand: Johannesburg

Kassin, S., Fein, S., \& Markus, H.R. (2011). Social Psychology. ( $8^{\text {th }}$ Ed. ). Linda Schreiber- Ganster: Belmont

Kaufman, Z. A., Kaufman, E. B., Dringus, S., Weiss, H. A., Delany-Moretlwe, S., \& Ross, D. A. (2013). P3. 387 Prevalence and Predictors of Rape Perpetration Among Male Secondary School Students in Peri-Urban Xhosa Communities in South Africa. Sexually Transmitted Infections, 89 (Suppl 1), A270-A270.

Kjellgren, C., Priebe, G., Svedin, C.G., \& Langstrom, N. (2010). Sexually coercive behaviour in male youth: Population survey of general and specific risk factors. Archives of Sexual Behaviour, Vol 39 (5), 1161-1169. Doi: 10.1007/s10508-009-9572-9.

Kopko, K. (2007). Parenting styles and Adolescents.Department of Human Development. Cornell University:

Langa, M. M. (2012). Becoming a man: Exploring multiple voices of masculinity amongst a group of young adolescent boys in Alexandra Township, South Africa (Doctoral dissertation, University of Witwatersrand).

Larsen, K. (2008). Problem Behavior Theory. Weber State University: Utah

Louw, D., \& Louw, A. (2007).Child and Adolescent Development.Department of Psychology, University of Free State: Bloemfontein

Leedy, P.D., \& Ormrod, J.E. (2005). Practical research. Planning and design.(8th edition.) Pearson Prentice Hall: Upper Saddle River, New Jersey.

Malan, M. (2013).Gender Violence: creating a new normal for South Africa's men. Mail \& Gaurdian, Johannesburg.

Manlove, J., Logan, C., Moore, K., \& Ikramullah, E. (2010). Pathways from Family Religiosity toAdolescent Sexual Activity and Contraceptive Use. Perspectives on Sexual and Reproductive Health. Vol 40 (2), 105-117. DOI: 10.1363./4010508

Mawson, P., \& Basson, P. (2011). The experience of violence by male juvenile offenders convicted of assault: A descriptive phenomenological study. Volume 11,(1)

Morkel, A.V., Wibbelsman, C., \& Seigal, W.M. (2011).Male adolescent sexual and reproductive Health Care.Pedaitrics Incorporated, Pediatrics Volume. 128, no. 6

Moodley. S.V, Matjila, M.J, Moosa, M. (2010). Epidemology of substance abuse use among secondary school learners in Atteridgeville, Gauteng.

Netland, J.D . (2010). Measuring Psychopathy traits and antisocial behavior in three groups of male adolescent sex offenders and male non-sexual delinquents. University of Minnesota:

Pastarino, E. \& Doyle- Portillo, S . (2011).What is Psychology.Wardsworth: Belmont

Peacock, D., Redpath, J., Weston,M., Evans, K., Daub,A., \& Greig, A. (2008). Literature Review on Men, Gender, Health and HIV and AIDS in South Africa. Sonke Gender Justice Network: Johannesburg.

Peterson, I., Bhana, A., \& Mckay, M. (2005). Sexual Violence and Youth in South Africa: The need for Community-Based Prevention Interventions. Child abuse and Neglect, 29, 1233-1248: Elsevier Limited.

Ryckman, R.M. (2009). Theories of Personality. Thomson Wadsworth: Belmont.

Shenton, A.K. (2004). Strategies for ensuring trustworthiness in qualitative research projects. Thesis, Northumbia University: United Kingdom

Sinkovizs, R.R., Penz, E., Ghauri, P. N. (2008). Enhancing business. Department of International Business, Manchester Business School. Manchester: United Kingdom

Taylor, K. R. (2013). " Prevention starts at home": mapping the discourse parents who work in sexual assault-related fields create with their children about sexual assault (Doctoral dissertation).

Testa, M., Hoffman, J.H., Livingston, J.A., \& Turrisi, R. (2010). Preventing college women's sexual victimization through paren based intervention: A randomized controlled trial.

Torerai, E. (2013). The Star Newspaper. Johannesburg

Underwood, L.A., Robinson, S.B., Mosholder, E. \& Warren, K.M. (2008). Sex offender care for adolescents in secure care: Critical factors and counseling strategies. United States: Elsevier Limited

Wahyuni, D. (2012). The Research Design Maze: Understanding paradigms, cases, methods and methodologies. Volume 10, 1

Wechsberg, W. M., Myers, B., Reed, E., Carney, T., Emanuel, A. N., \& Browne, F. A. (2013). Substance use, gender inequity, violence and sexual risk among couples in Cape Town. Culture, health \& sexuality, (ahead-of-print), 1-16.

Weisz, A.N., \& Black, B.M. (2009). Evaluating a sexual assault and dating violence prevention program for urban youths. Social Work Research, Vol 25 (2), 89-100

Wilson, R.J.W., Fitzharris, J.L., \& Morrissey, K.M. (2004). Adolescent and parent perceptions of media influence on adolescent sexuality. Urban Publisher Incorporated, Volume 39, no. 154: 309

Zastrow, C., \& Kirst-Ashman K.K. (2007). Understanding human behaviour and thesocial environment. United States of America: Thomson Brooks/Cole. 